\title{
Japan's successful launch paves way for interplanetary missions
}

[TOKYO] The world's first space-based radiotelescope was launched last week by Japan's Institute of Space and Astronautical Science (ISAS). The event not only marked the start of a major international project in Very Long Baseline Interferometry (VLBI), but was also the first launch for ISAS using a more powerful launcher, the $\mathrm{M}-\mathrm{V}$ rocket, which will open up opportunities for lunar and interplanetary missions.

The radiotelescope satellite was named the Highly Advanced Laboratory for Communications and Astronomy (HALCA) after launch. But it is more popularly known by the acronym VSOP, which stands for VLBI Space Observatory, Programme, and is also a grading of French brandy, a favourite drink of Masaki Morimoto of Japan's Nobeyama Radio Observatory who played a key role in dreaming up the project.

The satellite occupies a highly eccentric orbit ranging between a few hundred and $21,000 \mathrm{~km}$ in height. After a series of perigeeraising manoeuvres to bring it to higher altitude, the next critical step will be the opening of the telescope's eight-metre antenna.

If that is successful, the telescope will, operating in conjunction with groundbased telescopes, provide the longest baselines ever for VLBI of up to $30,000 \mathrm{~km}$ three times those achievable on Earth. This will, for example, allow detailed imaging of the centre of active galaxies, as well as studies of spot sizes in maser sources (see Nature 381, 463; 1996).

Furthermore, by linking up with the Australia Telescope in the Southern Hemisphere, the project offers the first all-sky mapping instrument for radioastronomy. Eventually, more than 25 ground-based radiotelescopes will join the project.

The M-V solid fuel rocket used to launch the satellite is considerably more powerful than its predecessor, the M-3SII. The launch marks the end of a bizarre era in which ISAS rockets were limited by government decree to a tail diameter of 1.41 metres, in order to prevent competition with the bigger National Space Development Agency. The rocket can launch large satellites of up to $1,800 \mathrm{~kg}$ into low Earth orbit and carry small payloads to the Moon and nearby planets.

The M-V's next mission, due for launch this summer, is Lunar- $\mathrm{A}$, a spacecraft that will drop three penetrators from lunar orbit on to widely spaced locations on the Moon's surface. The penetrators, which have been designed to withstand impact at close to the speed of sound, will carry tiny seismometers, for measuring 'moonquakes', and heat flow probes. The data collected will be relayed to Earth via the orbiting spacecraft (see Nature 344, 693: 1990).

Next year, ISAS is scheduled to send a probe to orbit Mars. The Planet-B mission will stretch the capabilities of the $M-V$ rocket

\section{Insurers agree moratorium on gene data}

[LONDON] British insurance companies have provisionally agreed that, for an initial period of two years, they will not use genetic information about individuals in issuing life insurance policies linked to house mortgages

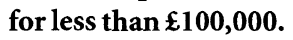

But the companies are insisting on the right to access to the results of such tests if they have been carried out. And they will also be free to use genetic information in calculating policies covering mortgages whose value is greater than $£ 100,000$, and for other forms of life cover.

The guidelines, which were released this week, have been drawn up by a panel of the Association of British Insurers (ABI) in response to growing public concern at potential discrimination against those revealed to have a genetic susceptibility to a particular disease.

The guidelines are intended to act as minimum rules of behaviour for all insurance companies belonging to the $\mathrm{ABI}$.
Individual companies will be free to adopt more restrictive policies - such as refusing to use any genetic information in assessing life insurance risks - if they choose to do so.

The proposal inevitably represents a compromise. Insurance companies continue to insist that, if they do not retain the rights to raise insurance rates for those likely to develop a fatal disease, the result will be unfairly increased premiums for all policyholders. But many are aware of the bad publicity generated by their handling of the HIV issue. A question on application forms about whether an applicant had taken an HIV test has since been dropped.

"Insurance companies must continue to see the results of genetic tests so they can monitor developments and gauge any financial impact on their company," says Tony Baker, deputy director general of the ABI. "However, the industry will not ask anyone to take a genetic test when applying for life insurance."

\section{IMAGE \\ UNAVAILABLE \\ FOR COPYRIGHT REASONS}

Bright prospects? The launch of the $M-V$ rocket ends a period of restriction on tail size.

to its limits, and will require extremely lightweight onboard equipment to keep the spacecraft's weight down to $186 \mathrm{~kg}$ (excluding fuel) so that it can reach Mars with the limited thrust provided by the $\mathrm{M}-\mathrm{V}$ rocket.

Its main mission is to observe the upper martian atmosphere and its interaction with the solar wind. But it will also carry a camera and a dust counter (see Nature 353, 8; 1991).

The most ambitious project of all, however, is the MUSES-C mission, scheduled for launch in January 2002. This will visit the asteroid Nereus, during its passage close to Earth, to collect a sample of the asteroid surface and return it to Earth in 2006. The spacecraft will use a novel 'ion thruster' in which xenon ions are accelerated by highvoltage electrodes to generate a small thrust.

On approaching the asteroid, which is only about $1 \mathrm{~km}$ in diameter and of unknown shape, the spacecraft will use instrumentation that includes an optical navigation camera, light detection and ranging, laser range finders and fan-beam sensors to select a suitable spot to touch down and grab a sample.

On return to Earth, a re-entry capsule will plunge straight into the Earth's atmosphere directly from the interplanetary return trajectory at a velocity of more than $12 \mathrm{~km}$ per second. The capsule will be subject to a heat transfer rate 30 times higher than that of the US Space Shuttle, and providing it survives, will then deploy a parachute for a soft landing.

DavidSwinbanks 